\section{Detection of progressive macular thickness loss using optical coherence tomography in glaucoma suspect and glaucomatous eyes}

\author{
Abstract \\ Aims To examine the rate of macular \\ thickness loss using time-domain optical \\ coherence tomography (OCT) in functionally \\ progressing versus non-progressing eyes, \\ determined by standard automated perimetry \\ (SAP). \\ Methods Glaucoma suspects (GS) and \\ glaucomatous (G) eyes underwent SAP and \\ OCT imaging every 6 months. Functional \\ progression was determined using pointwise \\ linear regression, defined as 2 contiguous \\ locations losing $\geq 1.0 \mathrm{~dB} /$ year at $P<1.0 \%$ in \\ the same hemifield. The annual rate of \\ macular thickness loss was calculated from \\ inner and outer regions of the macular map. \\ Results 72 eyes (43 GS and 29G) with \\ $\geq 30$ months of follow-up were enroled. \\ Fourteen eyes demonstrated SAP progression. \\ The annual rate of macular thickness loss \\ ( $\mu \mathrm{m} /$ year) in progressing eyes was faster \\ (all $P<0.05$ ) than non-progressing eyes in \\ temporal outer $(-1.90 \pm 2.97$ vs $0.33 \pm 2.77)$, \\ nasal inner $(-1.70 \pm 2.66$ vs $0.14 \pm 2.76)$, \\ superior inner $(-2.15 \pm 4.57$ vs $0.51 \pm 2.99)$, \\ temporal inner quadrants $(-2.58 \pm 5.05$ vs \\ $-0.38 \pm 2.34)$, and the average of inner \\ macular quadrants $(-1.84 \pm 2.90 v s$ \\ $0.03 \pm 2.10)$. The rate of loss in the nasal \\ inner $(P=0.02)$ and temporal outer $(P=0.02)$ \\ macular regions was associated with \\ optic disc haemorrhage. \\ Conclusions Eyes with SAP progression \\ have significantly greater rates of macular \\ thickness loss consistent with glaucomatous \\ retinal ganglion cell atrophy, as compared \\ with non-progressing eyes.
}

PI Niles', DS Greenfield' ${ }^{1}$ M Sehi', N Bhardwaj', SM Iverson', YS Chung' and Advanced Imaging in Glaucoma Study Group $1,2,3,4$
'Bascom Palmer Eye Institute, Department of Ophthalmology, University of Miami Miller School of Medicine, Palm Beach Gardens, FL, USA

${ }^{2}$ Casey Eye Institute Department of Ophthalmology, Oregon Health and Science University, Portland, OR, USA

${ }^{3}$ University of Pittsburgh Medical Center, Pittsburgh, PA, USA

\section{Introduction}

Glaucoma is a progressive optic neuropathy in which there is a loss of retinal ganglion cells (RGCs) and their axons. ${ }^{1}$ It has been demonstrated that glaucomatous damage to the retinal nerve fibre layer (RNFL) precedes functional loss by as much as 5 years. $^{2-7}$ Loss of the RGCs and their axons is known to occur in the posterior pole, where approximately one-third of the RGC population resides. A significant association exists between loss of retinal thickness in the posterior pole and visual changes. ${ }^{8}$

Optical coherence tomography (OCT) is a high-resolution, micron scale, cross-sectional imaging modality that is based upon interferometry. ${ }^{9}$ OCT provides quantitative assessments of the retina and optic nerve by measuring the echo time delay and intensity of backscattered light from posterior segment structures. Cross-sectional studies have demonstrated that OCT can provide robust discrimination between normal and glaucomatous eyes ${ }^{10-12}$ and is capable of detecting progressive glaucomatous RNFL atrophy. ${ }^{13,14}$ Thus, the quantitative measures provided by OCT may serve as a useful adjunct to longitudinal assessment of visual function with standard automated perimetry (SAP) and optic nerve appearance using clinical
${ }^{4}$ Doheny Eye Institute, Department of Ophthalmology, Keck School of Medicine, University of Southern California, Los Angeles, CA, USA

Correspondence: M Sehi, Bascom Palmer Eye Institute, University of Miami Miller School of Medicine, 7101 Fairway Drive, Palm Beach Gardens, FL 33418, USA

Tel: + 1561515 1546; Fax: + 15613558600 . E-mail: msehi@med. miami.edu

Received: 11 January 2012 Accepted in revised form: 19 March 2012 Published online: 11 May 2012

Meeting Presentation: Paper presentation at the annual meeting of the Association for Research in Vision and Ophthalmology, Fort 2011. Lauderdale, FL, May 5 , 
examination stereoscopic optic disc photography in detecting glaucoma progression.

In cross-sectional studies, OCT-derived macular thickness has been shown to be well correlated with changes in visual function and RNFL ${ }^{15-19}$ consistent with glaucomatous RGC atrophy. We hypothesized that progressive retinal thickness atrophy in the macular region could represent a surrogate biomarker for detecting progressive glaucomatous structural change over time. This prospective analysis was designed to compare the rate of macular thickness loss measured with OCT in progressing versus non-progressing eyes as defined using standard automated perimetry (SAP).

\section{Materials and methods}

This was a prospective longitudinal cohort study. Participants consisted of glaucoma suspects and glaucoma patients who were prospectively enroled in the Advanced Imaging in Glaucoma Study (AIGS) conducted at Bascom Palmer Eye Institute, Palm Beach Gardens, FL, USA and were examined every 6 months. Informed consent was obtained from all subjects using a consent form approved by the Institutional Review Board of the University Of Miami Miller School Of Medicine, which was in agreement with the provisions of Declaration of Helsinki. One study eye was chosen from each patient and was selected based on whichever eye was first determined to demonstrate SAP progression. If neither eye demonstrated progression, the study eye was randomly selected. Eyes meeting inclusion criteria with $\geq 30$ months of follow-up were included. Inclusion criteria common to both groups consisted of spherical equivalent refractive error between -7.00 and $+3.00 \mathrm{D}$ sphere, best corrected visual acuity (BCVA) of 20/40 or better, age between 40 and 79 years, and no prior history of intraocular surgery except for uncomplicated cataract extraction. Subjects with ocular disease other than glaucoma or cataract, parapapillary atrophy extending to $1.7 \mathrm{~mm}$ from the centre of the optic disc, unreliable SAP, or poor quality OCT images were excluded.

Glaucoma suspects consisted of eyes with ocular hypertension (OHT) characterized by an intraocular pressure $(\mathrm{IOP}) \geq 24 \mathrm{~mm} \mathrm{Hg}$ with normal optic discs and normal SAP, or those with glaucomatous optic neuropathy on funduscopic examination and review of stereoscopic optic disc photographs and normal SAP (preperimetric glaucoma; PPG). Glaucomatous optic neuropathy was defined as neuroretinal rim narrowing to the optic disc margin, notching, excavation or RNFL defect. Glaucomatous eyes had glaucomatous optic nerve damage, and corresponding abnormal SAP defined as an abnormal glaucoma hemifield test, and pattern standard deviation outside $95 \%$ normal limits. Eyes with SAP abnormalities had at least one confirmatory visual-field examination. All patients underwent a baseline examination consisting of a complete ophthalmic examination including slit-lamp biomicroscopy, gonioscopy, Goldmann applanation tonometry, ultrasound pachymetry, dilated stereoscopic examination and photography of the optic disc, SAP, and OCT imaging. All eyes underwent follow-up SAP and OCT imaging at 6-month intervals. During the follow-up period, each patient was treated at the discretion of the attending physician.

\section{OCT imaging and analysis}

OCT imaging was performed in a standardized fashion without pharmacologic pupil dilation, unless the pupil was too small to permit imaging. Poor quality scans were excluded, including scans with motion artefact, poor centration, segmentation error, or signal strength $<5$. The OCT calibration was checked annually by authorized technicians in accordance with the manufacturer's guidelines. A commercially available Stratus OCT (Carl Zeiss Meditec, Dublin, CA, USA; software version 5.0) was used to perform macular imaging, using the fast macular thickness map scan which utilizes six 6-mm radial scans centred on the fovea, each comprised of 128 individual A-scans, and an acquisition time of $1.9 \mathrm{~s}$. The OCT software determines the macular thickness as the distance between the vitreoretinal interface and the hyperreflective band corresponding to the retinal pigment epithelium. These scans are processed to produce a topographic map of the macula using three concentric circles with diameters of 1,3 , and $6 \mathrm{~mm}$ that divide the macular thickness map into three zones: fovea, inner macula, and outer macula. The inner and outer zones are further divided into four quadrants by two diagonal lines. Thus, a total of nine areas (fovea, superior outer, superior inner, inferior outer, inferior inner, temporal outer, temporal inner, nasal outer, and nasal inner) are available for analysis. OCT parameters investigated in this study consisted of inner macular thickness (average, temporal, superior, nasal, and inferior), outer macular thickness (average, temporal, superior, nasal, and inferior), and average total macular thickness (inner and outer zones) calculated as the weighted average of the sectoral macular thickness measurements excluding the fovea. The weighting process is part of the OCT-automated software for the calculation of sectoral macular thickness. Each OCT measurement was repeated twice at each session and the average of two high-quality images was included in the analysis. When a patient had one scan of sufficient quality and one scan of insufficient quality, the scan with 
insufficient quality was excluded and the scan with sufficient quality was included in the analysis.

\section{Assessment of progression using standard automated perimetry}

SAP was performed using the Swedish Interactive Threshold Algorithm strategy (Humphrey Field Analyser 750 II-I, 24-2 SITA Standard; Carl Zeiss Meditec Dublin, CA, USA). Only reliable test results $(<33 \%$ fixation losses, false-negative results, and false-positive results) were included. All patients were familiar with automated perimetry and had undergone a minimum of two visual field tests before study enrolment.

SAP progression was defined using pointwise linear regression (PLR) analysis of SAP sensitivity values using Progressor software (Version 3.3; Medisoft, Leeds, UK), generating slopes to analyse the rate of global and local sensitivity change and the associated level of significance ( $P$-values). Progression with PLR criteria was defined as 2 contiguous locations in the same hemifield that were losing $\geq 1.0 \mathrm{~dB} /$ year with $P<0.01 .^{20,21}$

All patients had visual fields and OCT imaging performed on the same day. The average number of visual fields included in the progression analysis was $9.75 \pm 2.2$ (range 5-15) for each patient. During the follow-up period, 72 eyes had a total of 705 visits, 705 visual fields, and 1410 OCT images available, of which 29 glaucomatous eyes had 257 visual fields and 514 OCT images available, and 43 glaucoma suspect eyes had 448 visual fields and 896 OCT images available. Of the total of 1410 OCT images acquired during the study, 21 scans $(1.5 \%)$ were excluded from analysis owing to insufficient quality.

\section{Statistical analysis}

Statistical analysis was performed using JMP software version 8.0 (SAS Inc., Cary, NC, USA) and SPSS 18 (SPSS, Chicago, IL, USA). The rate of macular thickness loss over time ( $\mu \mathrm{m} /$ year) was calculated for each eye using linear regression analysis as the amount of change in macular thickness in $\mu$ m per each follow-up year. Clinical characteristics of the study population were compared using analysis of variance (ANOVA) with Tukey Kramer HSD test, and $\chi^{2}$ tests. Linear mixed-effect models were constructed with both fixed and random effects included to evaluate the relationship between the slope of macular thickness loss and SAP progression over time and address-repeated longitudinal measurements over time. These models facilitated the analysis of all available data considering the group effects, and random patient effects. Categorical predictor variables included optic disc haemorrhage, diagnosis (perimetric glaucoma,
PG, or glaucoma suspect, GS), and the status of visual field progression. Continuous variables included baseline central corneal thickness (CCT), and IOP measures including mean, peak, and long-term IOP fluctuation (defined as peak-trough IOP during the follow-up period). Separate models were constructed to accommodate different measures of IOP. Random effects for 'patient' and 'eye nested within patient' were included in these models to accommodate serial dependence within eyes over time, as well as associations between the left and right eyes. All tests were two-sided and $P$-value of $<0.05$ was considered significant.

\section{Results}

Seventy-two eyes (43 glaucoma suspect, 29 glaucoma) of 72 patients (mean age $63.5 \pm 10.0$ years, range $40-80$ ) were enroled. The mean length of follow-up was $4.4 \pm 1.2$ (range 2.5-11) years. Table 1 describes the clinical characteristics of the study population. Baseline CCT, IOP and visual field mean deviation (MD) were statistically different between glaucoma suspects and glaucoma patients.

Table 1 Clinical characteristics of the study population at baseline $(n=72)$

\begin{tabular}{|c|c|c|c|}
\hline Parameter & $\begin{array}{c}\text { Glaucoma } \\
\text { suspect } \\
(\mathrm{n}=49 \text { eyes })\end{array}$ & $\begin{array}{c}\text { Glaucoma } \\
(\mathrm{n}=23 \text { eyes })\end{array}$ & P-value \\
\hline Age (years) & $62.2 \pm 9.6$ & $65.3 \pm 9.9$ & $0.20^{\mathrm{a}}$ \\
\hline $\begin{array}{l}\text { Gender } \\
\text { Male } \\
\text { Female }\end{array}$ & $\begin{array}{l}16 \\
27\end{array}$ & $\begin{array}{l}11 \\
18\end{array}$ & $0.33^{\mathrm{b}}$ \\
\hline $\begin{array}{l}\text { Race } \\
\text { White } \\
\text { Hispanic } \\
\text { Black } \\
\text { Others }\end{array}$ & $\begin{array}{r}34 \\
2 \\
5 \\
2\end{array}$ & $\begin{array}{r}24 \\
0 \\
2 \\
3\end{array}$ & $0.93^{\mathrm{b}}$ \\
\hline $\begin{array}{l}\text { Disc haemorrhage } \\
\text { Present } \\
\text { Absent }\end{array}$ & $\begin{array}{r}1 \\
42\end{array}$ & $\begin{array}{r}6 \\
23\end{array}$ & $0.92^{\mathrm{b}}$ \\
\hline $\begin{array}{l}\text { Lens status } \\
\text { Phakic } \\
\text { Pseudophakic }\end{array}$ & $\begin{array}{r}37 \\
6\end{array}$ & $\begin{array}{r}23 \\
6\end{array}$ & $0.50^{\mathrm{b}}$ \\
\hline $\begin{array}{l}\text { Central corneal } \\
\text { thickness }(\mu \mathrm{m})\end{array}$ & $555.9 \pm 33.2$ & $537.3 \pm 39.2$ & $0.03^{\mathrm{a}}$ \\
\hline $\begin{array}{l}\text { Intraocular pressure } \\
(\mathrm{mm} / \mathrm{Hg})\end{array}$ & $18.1 \pm 3.9$ & $12.9 \pm 3.5$ & $<0.001^{\mathrm{a}}$ \\
\hline $\begin{array}{l}\text { Standard automated p } \\
\text { MD } \\
\text { PSD }\end{array}$ & $\begin{array}{l}\text { etry } \\
-1.46 \pm 0.4 \\
1.74 \pm 1.27\end{array}$ & $\begin{array}{l}-5.80 \pm 4.1 \\
1.86 \pm 1.29\end{array}$ & $\begin{array}{l}<0.001^{\mathrm{a}} \\
0.72\end{array}$ \\
\hline $\begin{array}{l}\text { Progression status usi } \\
\text { Progressed } \\
\text { Non-progressed }\end{array}$ & $\begin{array}{r}7 \\
36\end{array}$ & $\begin{array}{r}7 \\
22\end{array}$ & $0.52^{\mathrm{b}}$ \\
\hline
\end{tabular}

Abbreviations: $\mathrm{MD}$, mean deviation; PSD, pattern standard deviation; PLR, pointwise linear regression analysis of visual field sensitivity values. ${ }^{\mathrm{a} A n a l y s i s}$ of variance.

${ }^{\mathrm{b}} \chi^{2}$ test. 
The AIGS protocol defines the glaucoma suspect group as those with ocular hypertension (OHT) and/or preperimetric glaucoma (PPG). We compared OHT and PPG groups, respectively, with regard to age (61.9 \pm 9.7 , $63.1 \pm 10.3, P=0.93)$, CCT $(561.3 \pm 35.3,546.9 \pm 27.1$; $P=0.36)$, baseline IOP $(21.4 \pm 3.3,16.2 \pm 3.5 ; P<0.001)$, gender $(P=0.27)$, race $(P=0.13)$, and progression status $(P=0.70)$. The demographic and clinical characteristics of the OHT and PPG groups were similar with no difference in SAP MD $(-0.09 \pm 0.77,0.16 \pm 0.91 ; P=0.97)$ or PSD $(1.53 \pm 0.34$ vs $1.42 \pm 0.30, P=0.92)$. The PSD was significantly different between the perimetric glaucoma and PPG $(P<0.001)$, and perimetric glaucoma and OHT groups $(P<0.001)$.

Figure 1 illustrates the right eye of a 75-year-old patient with normal-tension glaucoma and demonstrates progressive glaucomatous visual field damage associated with progressive diffuse macular thickness loss. The top panel (baseline examination) demonstrates an average total macular thickness of $195.5 \mu \mathrm{m}$ (left), advanced glaucomatous optic nerve head cupping with disc haemorrhage (arrow, middle) and inferior arcuate scotoma on standard automated perimetry (right). After 4 years of follow-up, the bottom panel demonstrates diffuse macular thickness loss with average total macular thickness of $165.13 \mu \mathrm{m}$ ( $-7.6 \mu \mathrm{m}$ /year), progressive optic atrophy, and progressive visual field loss (annual decline in visual field index $-4 \%$ /year).

A total of 14 eyes (19\%), composed of 6 glaucoma suspect and 8 glaucomatous eyes, demonstrated SAP

Table 2 Baseline OCT macular thickness measurements $(\mu \mathrm{m})$ in eyes classified as having visual field progression and nonprogression ( $n=72$ eyes)

\begin{tabular}{lccc}
\hline $\begin{array}{l}\text { Macula Parameter } \\
(\mu \mathrm{m})\end{array}$ & $\begin{array}{c}\text { Progressing } \\
\text { eyes }(\mathrm{n}=14)\end{array}$ & $\begin{array}{c}\text { Non-progressing } \\
\text { eyes }(\mathrm{n}=58)\end{array}$ & P-value $^{\mathrm{a}}$ \\
\hline Temporal inner & $248.8 \pm 22.6$ & $244.1 \pm 20.6$ & 0.76 \\
Superior inner & $262.5 \pm 22.5$ & $256.7 \pm 22.2$ & 0.81 \\
Nasal inner & $267.1 \pm 22.1$ & $259.2 \pm 23.3$ & 0.88 \\
Inferior inner & $257.1 \pm 24.1$ & $252.1 \pm 22.8$ & 0.76 \\
Temporal outer & $206.7 \pm 20.5$ & $202.7 \pm 17.9$ & 0.74 \\
Superior outer & $224.1 \pm 20.6$ & $220.1 \pm 19.7$ & 0.75 \\
Nasal outer & $238.5 \pm 18.7$ & $238.0 \pm 22.1$ & 0.53 \\
Inferior outer & $207.7 \pm 18.7$ & $207.3 \pm 20.4$ & 0.53 \\
Inner average & $258.9 \pm 21.9$ & $253.0 \pm 21.3$ & 0.81 \\
Outer average & $219.3 \pm 17.9$ & $217.0 \pm 18.2$ & 0.66 \\
Total average & $239.1 \pm 19.6$ & $235.0 \pm 19.3$ & 0.75 \\
\hline
\end{tabular}

Abbreviations: Inner average, average of inner macular parameters; outer average, average of all outer macular parameters; total average, average of all parameters.

ane-way ANOVA.

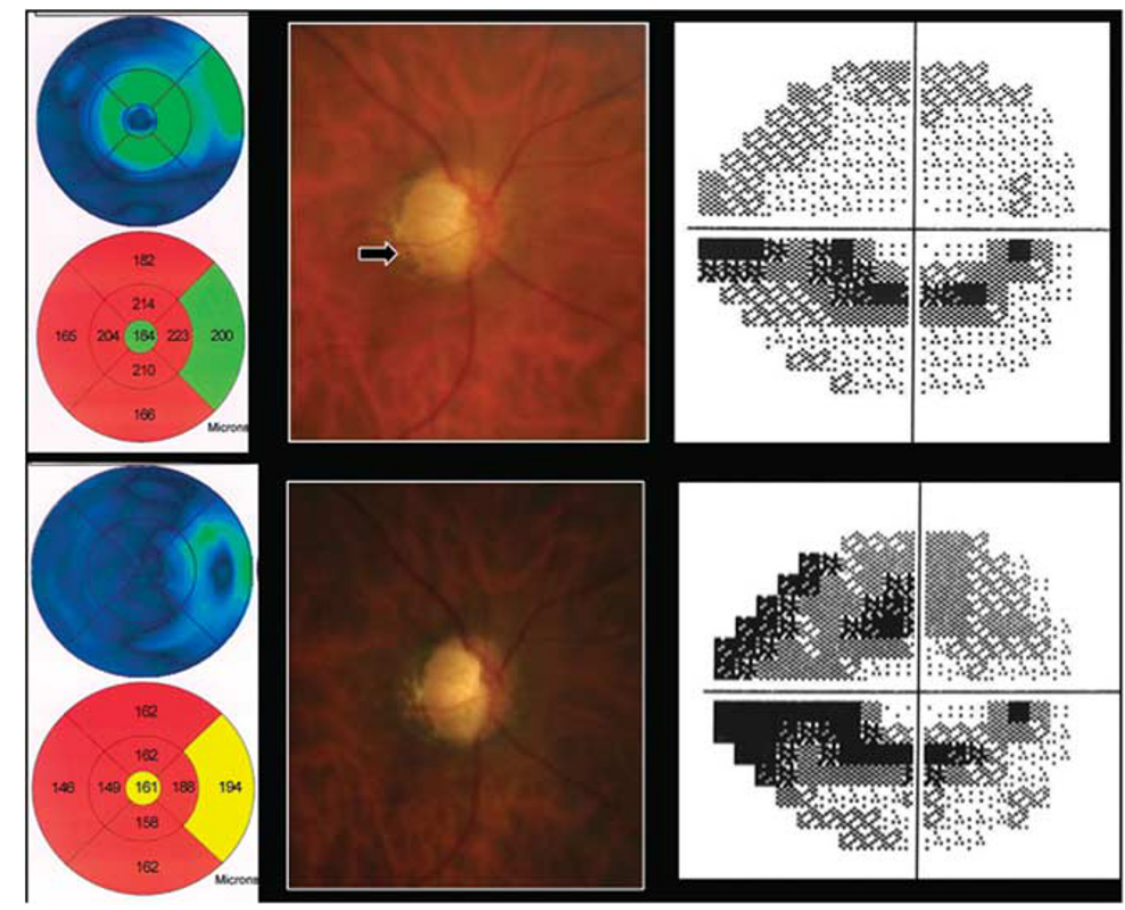

Figure 1 Right eye of a patient with normal-tension glaucoma demonstrates progressive glaucomatous visual field damage associated with progressive diffuse macular thickness loss. The top panel (baseline examination) demonstrates an average total macular thickness of $195.5 \mu \mathrm{m}$ (left), advanced glaucomatous optic nerve head cupping with disc haemorrhage (arrow, middle) and inferior arcuate scotoma on standard automated perimetry (right). After 4 years of follow-up, the bottom panel demonstrates diffuse macular thickness loss with average total macular thickness of $165.13 \mu \mathrm{m}(-7.6 \mu \mathrm{m} /$ year $)$, progressive optic atrophy, and progressive visual field loss (annual decline in visual field index, $-4 \%$ ). 
Table 3 Mean and 95\% confidence intervals for rate of change of macular thickness parameters ( $\mu \mathrm{m} /$ year) in eyes classified as having visual field progression and non-progression $(n=72$ eyes)

\begin{tabular}{|c|c|c|c|c|c|}
\hline \multirow[t]{2}{*}{ Macula parameter } & \multicolumn{2}{|c|}{ Progressing eyes $(\mu \mathrm{m} /$ year $)(\mathrm{n}=14)$} & \multicolumn{2}{|c|}{ Non-progressing eyes $(\mu \mathrm{m} /$ year $)(\mathrm{n}=58)$} & \multirow[t]{2}{*}{ P-value ${ }^{\mathrm{a}}$} \\
\hline & Mean $\pm S D$ & $95 \% C I$ & Mean $\pm S D$ & $95 \% \mathrm{CI}$ & \\
\hline Temporal Inner & $-2.58 \pm 5.05$ & $-5.50-0.34$ & $-0.38 \pm 2.34$ & $-0.99-0.24$ & 0.02 \\
\hline Superior inner & $-2.15 \pm 4.57$ & $-4.79-0.49$ & $0.51 \pm 2.99$ & $-0.27-1.30$ & 0.01 \\
\hline Nasal inner & $-1.70 \pm 2.66$ & -3.24 to -0.16 & $0.14 \pm 2.76$ & $-0.58-0.87$ & 0.03 \\
\hline Inferior inner & $-0.92 \pm 3.12$ & $-2.72-0.88$ & $-0.14 \pm 2.46$ & $-0.79-0.50$ & 0.32 \\
\hline Temporal outer & $-1.90 \pm 2.97$ & -3.61 to -0.18 & $0.33 \pm 2.77$ & $-0.40-1.06$ & 0.01 \\
\hline Superior outer & $-0.91 \pm 2.28$ & $-2.22-0.41$ & $-0.11 \pm 2.85$ & $-0.86-0.64$ & 0.34 \\
\hline Nasal outer & $1.27 \pm 2.90$ & $-0.41-2.95$ & $-0.39 \pm 3.69$ & $-1.36-0.58$ & 0.12 \\
\hline Inferior outer & $-0.45 \pm 2.16$ & $-1.70-0.80$ & $-0.41 \pm 3.31$ & $-1.28-0.46$ & 0.97 \\
\hline Inner average & $-1.84 \pm 2.90$ & -3.51 to -0.15 & $0.03 \pm 2.10$ & $-0.52-0.59$ & 0.01 \\
\hline Outer average & $-0.50 \pm 0.43$ & $-1.42-0.43$ & $-0.15 \pm 1.90$ & $-0.65-0.35$ & 0.26 \\
\hline Total average & $-1.17 \pm 2.07$ & $-2.36-0.03$ & $-0.06 \pm 1.78$ & $10.52-0.41$ & 0.04 \\
\hline
\end{tabular}

Abbreviations: SD, standard deviation; inner average, average of inner macular parameters; outer average, average of all outer macular parameters; total average, average of all parameters.

${ }^{\mathrm{a} A n a l y s i s ~ o f ~ v a r i a n c e ~(A N O V A) . ~}$

progression during the follow-up period. Table 2 illustrates the baseline macular thickness values in progressing and non-progressing eyes. Baseline macular thicknesses were similar $(P>0.05)$ in all macular sectors, and macular sector averages between progressing and non-progressing eyes. Table 3 demonstrates the mean \pm SD and $95 \%$ confidence intervals for the slope of macular thickness loss ( $\mu \mathrm{m} /$ year) measured using OCT in eyes judged to have progressing and non-progressing visual fields. The annual rate of macular loss ( $\mu \mathrm{m} /$ year $)$ was significantly greater in the temporal inner macula $(P=0.02)$, the superior inner macula $(P<0.01)$, the nasal inner macula $(P=0.03)$, the temporal outer macula $(P=0.01)$, the average of the inner macular parameters $(P=0.01)$, and the average of all 8 parameters $(P=0.04)$. A positive rate of mean macular thickness change over time was observed in 4 macular parameters in nonprogressing eyes, but the slope was not significantly different from zero for any of these parameters $(P>0.05)$.

We examined the relationship between the rate of change in macular thickness and visual function among progressing eyes $(n=14)$. Four of 14 eyes $(28.6 \%)$ had progressive visual field loss within the central $10^{\circ}$ eccentricity. Table 4 illustrates the correlation between macular thickness change ( $\mu \mathrm{m} /$ year), average slope for visual field test locations showing progression ( $\mathrm{dB} /$ year), and the mean slope of the visual field among eyes with SAP progression (dB/year). Superior inner, nasal inner, and superior outer macular thickness $\left(R^{2}=0.67,0.57\right.$, and 0.41 , respectively) were significantly $(P<0.001,0.002$, and 0.01 ) correlated with the slope of progressing visual points. Superior inner, inferior inner, and nasal outer macular thickness $\left(R^{2}=0.67,0.30\right.$, and 0.27 , respectively) were significantly $(P<0.001,0.04$, and 0.05$)$ correlated
Table 4 Relationship between rate of macular thickness loss $(\mu \mathrm{m} /$ year), average slope for visual field test locations showing progression ( $\mathrm{dB} /$ year), and slope of the visual field $(\mathrm{dB} /$ year) among eyes with visual field progression $(n=14)$

\begin{tabular}{lccccc}
\hline $\begin{array}{l}\text { Macula parameters } \\
(\mu \mathrm{m} / \text { year })\end{array}$ & \multicolumn{2}{c}{$\begin{array}{c}\text { Slope of progressing test } \\
\text { locations }\end{array}$} & & \multicolumn{2}{c}{$\begin{array}{c}\text { Slope of all test } \\
\text { locations }\end{array}$} \\
\cline { 2 - 3 } \cline { 6 - 6 } & $\mathrm{R}^{2}$ & P-value & & $\mathrm{R}^{2}$ & P-value \\
\hline Temporal inner & 0.15 & 0.17 & & 0.002 & 0.96 \\
Superior inner & 0.67 & $<0.001$ & & 0.63 & $<0.001$ \\
Nasal inner & 0.57 & 0.002 & & 0.02 & 0.60 \\
Inferior inner & 0.02 & 0.66 & & 0.30 & 0.04 \\
Temporal outer & 0.18 & 0.13 & & 0.04 & 0.50 \\
Superior outer & 0.41 & 0.01 & & 0.11 & 0.25 \\
Nasal outer & 0.03 & 0.55 & & 0.27 & 0.05 \\
Inferior outer & 0.02 & 0.62 & & 0.27 & 0.06 \\
Inner average & 0.03 & 0.54 & & 0.01 & 0.70 \\
Outer average & 0.02 & 0.63 & & 0.02 & 0.63 \\
Total average & 0.03 & 0.58 & & 0.02 & 0.66 \\
\hline
\end{tabular}

Abbreviations: inner average, average of inner macular parameters; outer average, average of all outer macular parameters; total average, average of all parameters.

with the mean slope of the visual field. We also evaluated the relationship between the slope of change in the central 4 and 16 test locations ( $\mathrm{dB} /$ year) and the slope of change in the inner macula, and average macular thickness ( $\mu \mathrm{m} /$ year) among progressing eyes $(n=14)$. There was no association between the rate of central visual field loss and the rate of macular thickness loss in the average, inner, and outer regions (all pairwise correlations: $r<0.09, P>0.05)$.

Using linear mixed-effects models, we examined the associations between the rate of macular thickness loss in different regions ( $\mu \mathrm{m} /$ year), and the follow-up period, 
IOP, CCT, SAP MD, SAP pattern standard deviation (PSD), disc haemorrhage, the variance in macular signal strength, and the diagnosis of glaucoma and visual field progression. We found that the rate of loss in the nasal inner $(P=0.02)$ and temporal outer $(P=0.02)$ macular region were significantly associated with occurrence of optic disc haemorrhage during the follow-up period.

\section{Discussion}

Detecting progressive loss of the RGCs and their axonal fibres is a critical aspect of glaucoma diagnosis, monitoring, and management, and is facilitated by digital ocular imaging technologies. OCT is capable of detecting progressive glaucomatous RNFL atrophy. $22,23,13,24,25$ Medeiros and colleagues ${ }^{23}$ reported a patient in whom progressive RNFL atrophy was detected, using OCT 70 days following traumatic optic neuropathy. Wollstein and colleagues ${ }^{24}$ demonstrated that OCT was at least as sensitive as standard automated perimetry in detection of glaucomatous progression among 64 eyes with primary open-angle glaucoma (POAG) followed for a mean of 4.7 years. Leung et al ${ }^{22}$ reported that Stratus OCT detected variable rates of RNFL thickness loss (median loss $-3.3 \mu \mathrm{m} /$ year) among a cohort of 64 patients followed for 5 years. Defining progression as having a statistically significant negative trend in linear regression analysis, recent evidence ${ }^{26}$ demonstrates that OCT detected fewer eyes with progression compared with SAP visual field index and neuroretinal rim measurements with the Heidelberg Retinal Tomograph (Heidelberg Engineering, Heidelberg, Germany).

We conducted this analysis to compare rates of progressive glaucomatous macular atrophy as measured using OCT in eyes judged to have SAP progression or non-progression, based upon trend-analysis criteria. Although glaucoma is an optic nerve disorder, the fundamental defining pathology is localized at the level of the RGC. A significant proportion of RGC population resides in the macula, but is clinically undetectable on ophthalmoscopic examination. Several macular sectors, including the temporal inner macula, the superior inner macula, the nasal inner macula, the temporal outer macula, and the average of all macular sectors, excluding the fovea, demonstrated significant differences in the rates of macular atrophy in progressing versus nonprogressing eyes. These data shows that, in glaucomatous eyes without macular pathology, significant macular atrophy over time should heighten a clinician's suspicion of possible progression. We found a significant relationship between the rate of macular thickness loss and the rate of localized and diffuse visual field decline as measured using PLR. Macula thickness atrophy is a surrogate biomarker of progressive RGC loss. A $6 \mathrm{~mm}$ diameter macular map corresponds to visual angle of $\sim 10^{\circ}$ from fixation. Although not obtained in the present study, central 10-2 visual fields would be expected to demonstrate a more robust relationship between progressive loss of macular thickness and visual function. Kanadani $e t a^{27}$ examined the relationship between OCT macular thickness and central 10-2 visual field loss among 55 eyes with glaucoma and found very high rates of concordance among eyes that had at least one abnormal point-out of the 16 central points on the $24-2$ visual field. In the present study, progression occurred outside the central $10^{\circ}$ in $71 \%$ of eyes and may have escaped detection of progression RGC loss, using a macular map of this diameter. It should be noted that the rate of optic disc, RNFL, and visual field decline is characterized by considerable variability both within and between individuals. $^{26,28-33}$

To our knowledge, this is the first study to demonstrate progressive macular thickness atrophy in eyes with SAP progression. Our results differ from those published by Medeiros et al, ${ }^{23}$ in which no detectable macular thickness loss over time was detected among 31 of 253 (13\%) eyes that demonstrated progressive changes by stereophotographs and/or SAP. Differences in the methodology, study population, and analysis methods between our studies likely contributed to differences in these outcomes. $\sim 40 \%$ of progressing eyes, in the study by Medeiros and colleagues, had isolated changes in the optic nerve head without concomitant SAP progression. Early structural changes before visual field changes may have therefore escaped detection in the macular region. Data to support this has been demonstrated by Tan $e t a^{34}$ who reported that eyes with pre-perimetric glaucoma had similar macular thickness measurements using OCT $(229.1 \pm 14.5 \mu \mathrm{m})$ as compared with normal eyes $(238.3 \pm 13.0 \mu \mathrm{m})$. Differences in the definition of visual field progression may also explain the disparities between our results. Previous studies ${ }^{20,35-38}$ have shown that different progression criteria do not necessarily identify the same eyes as progressing. The study by Medeiros and colleagues defined SAP progression using an event analysis derived from the Early Manifest Glaucoma Trial ${ }^{39}$ consisting of a change in three or more of the same test points on three follow-up consecutive tests. Our study utilized a trend-based analysis defined as 2 contiguous locations in the same hemifield that were losing $\geq 1.0 \mathrm{~dB} /$ year with $P<0.01^{20}$ which was selected as a sensitive and specific outcome measure for detecting localized functional progression ${ }^{40}$ as well as for comparison of rates of change in macular structure and visual function over time. Although our study was not 
designed to compare progressive glaucomatous changes in the macular region to circumpapillary RNFL, additional studies are currently in progress to compare the sensitivity and specificity of both structural outcome measures.

Advances in spectral domain OCT (SDOCT) technology have the potential to greatly enhance detection of progressive glaucomatous structural changes in the macular region over time. Segmentation of retinal layers, such as the ganglion cell complex ${ }^{34}$ consisting of the combined nerve fibre, ganglion cell, and inner plexiform layers, may enhance detection of localized glaucomatous changes. The faster speed of SDOCT (65x Stratus OCT) allows high-density scanning over a large region of the macula with less motion artefact, higher resolution, and improved repeatability could improve the ability to track glaucomatous thinning over time. Recent data ${ }^{41}$ has shown that SDOCT outperformed Stratus OCT in detecting more eyes with RNFL progression and fewer eyes with RNFL improvement, suggesting that SDOCT may detect changes in RNFL thickness sooner than the Stratus OCT owing to reduced measurement variability. Future studies are warranted to compare the sensitivity and specificity of GCC with total macular thickness for detection of glaucoma progression.

Our study has potential limitations. We enroled a relatively small sample size of glaucoma suspect and glaucoma patients in this prospective trial. In addition, patients were treated at the discretion of the physician, which could influence the rate of progression. Although we found that the rate of loss in the nasal inner and temporal outer macular region were significantly associated with occurrence of optic disc haemorrhage during the follow-up period, our study may be underpowered to identify risk factors associated with progressive macular thickness atrophy. Biologically, one would expect that the loss of RGCs and their axons should be strongly associated with a measurable loss of visual function. However, data from large prospective randomized clinical trials often demonstrate discordance in the timing for detecting a change in structure and visual function. For example, in the Ocular Hypertension Treatment Study, ${ }^{42}$ there were 69 optic disc endpoints and 44 visual field endpoints, but only 12 patients with both optic disc and visual field endpoints. In the European Glaucoma Prevention Study, ${ }^{43}$ there were 42 optic disc endpoints and 64 visual field endpoints, but no patients with both structure-based and functional endpoints. Our findings are similarly discordant. We speculate that longer follow-up periods may be required to demonstrate a more robust correlation between changes in macular thickness, optic disc haemorrhage, and visual field progression.
Our protocol consisted of central 24-2 threshold fields, and a large proportion of glaucomatous field defects were localized outside of the central 16 points. Central 10-2 visual field exams serve as a more robust strategy for assessing the structure-function relationship in the macular region. Test-retest variability and age-related macular changes may also limit the ability to use macular thickness measurements as a clinical endpoint for glaucoma progression. Lastly, it is important to emphasize that macular thickness measurements have limited use for monitoring glaucoma in eyes with macular co-morbidity. Thus, eyes with diabetic or agerelated maculopathy are not candidates for monitoring macular thickness changes as a strategy for glaucoma diagnosis or detection of glaucomatous progression.

In conclusion, OCT is useful for detection of glaucomatous structural progression and quantifying the velocity of progressive macular loss. Emerging therapeutic strategies, such as neuroprotection, emphasize the need to identify and measure the RGCs for glaucoma diagnosis and monitoring. The present study demonstrates that progressing eyes have a significantly greater rate of macular loss compared with non-progressing eyes. This rate of macular atrophy is correlated with the rate of visual field progression and may be a useful biomarker for glaucoma monitoring.

\author{
Summary \\ What was known before \\ - Optical coherence tomography provides robust \\ discrimination between normal and glaucomatous eyes. \\ What this study adds \\ - The annual rate of macular thickness loss in functionally \\ progressing eyes is faster than non-progressing eyes and \\ the rate of loss is associated with optic disc haemorrhage.
}

\section{Conflict of interest}

Dr. Greenfield has received research support from Carl Zeiss Meditec, Dublin, CA, USA. The other authors declare no conflict of interest.

\section{Acknowledgements}

NIH Grant R01-EY013516, Bethesda, Maryland; P30EY014801 University of Miami core grant; an unrestricted grant from Research to Prevent Blindness, New York, NY, USA; The Maltz Family Endowment for Glaucoma Research, Cleveland, OH, USA; a grant from Mr Barney Donnelley, Palm Beach, FL, USA; and The Kessel Foundation, Bergenfield, NJ, USA. The sponsor or 
funding organization had no role in the design or conduct of this research.

\section{References}

1 Quigley HA, Dunkelberger GR, Green WR. Retinal ganglion cell atrophy correlated with automated perimetry in human eyes with glaucoma. Am J Ophthalmol 1989; 107: 453-464.

2 Hoyt WF, Frisen L, Newman NM. Fundoscopy of nerve fiber layer defects in glaucoma. Invest Ophthalmol 1973; 12: 814-829.

3 Quigley HA, Flower RW, Addicks EM, McLeod DS. The mechanism of optic nerve damage in experimental acute intraocular pressure elevation. Invest Ophthalmol Vis Sci 1980; 19: 505-517.

4 Sommer A, Katz J, Quigley HA, Miller NR, Robin HA, Richter RC et al. Clinically detectable nerve fiber atrophy precedes the onset of glaucomatous field loss. Arch Ophthalmol 1991; 109: 77-83.

5 Quigley HA, Katz J, Derick RJ, Gilbert D, Sommer A. An evaluation of optic disc and nerve fiber layer examinations in monitoring progression of early glaucoma damage. Ophthalmology 1992; 99: 19-28.

6 Airaksinen PJ, Drance SM, Douglas GR, Mawson DK, Nieminen H. Diffuse and localized nerve fiber loss in glaucoma. Am J Ophthalmol 1984; 98: 566-571.

7 Harwerth RS, Carter-Dawson L, Shen F, al e. Ganglion cell lossess underlying visual field defects from experimental glaucoma. Invest Ophthalmol Vis Sci 1999; 40: 2242-2250.

8 Zeimer R, Asrani S, Zou S, Quigley H, Jampel H. Quantitative detection of glaucomatous damage at the posterior pole by retinal thickness mapping. A pilot study. Ophthalmology 1998; 105: 224-231.

9 Huang D, Swanson EA, Lin CP, Schuman JS, Stinson WG, Chang W et al. Optical coherence tomography. Science 1991; 254: 1178-1181.

10 Nouri-Mahdavi K, Nikkhou K, Hoffman DC, Law SK, Caprioli J. Detection of early glaucoma with optical coherence tomography (StratusOCT). J Glaucoma 2008; 17: 183-188.

11 Vessani RM, Moritz R, Batis L, Zagui RB, Bernardoni S, Susanna R. Comparison of quantitative imaging devices and subjective optic nerve head assessment by general ophthalmologists to differentiate normal from glaucomatous eyes. J Glaucoma 2009; 18: 253-261.

12 Park SB, Sung KR, Kang SY, Kim KR, Kook MS. Comparison of glaucoma diagnostic Capabilities of Cirrus HD and Stratus optical coherence tomography. Arch Ophthalmol 2009; 127: 1603-1609.

13 Lee EJ, Kim TW, Park KH, Seong M, Kim H, Kim DM. Ability of Stratus OCT to detect progressive retinal nerve fiber layer atrophy in glaucoma. Invest Ophthalmol Vis Sci 2009; 50: 662-668.

14 Sehi M, Greenfield DS. Assessment of retinal nerve fiber layer using optical coherence tomography and scanning laser polarimetry in progressive glaucomatous optic neuropathy. Am J Ophthalmol 2006; 142: 1056-1059.

15 Greenfield DS, Bagga H, Knighton RW. Macular thickness changes in glaucomatous optic neuropathy detected using optical coherence tomography. Arch Ophthalmol 2003; 121: 41-46.

16 Wollstein G, Schuman JS, Price LL, Aydin A, Beaton SA, Stark PC et al. Optical coherence tomography (OCT) macular and peripapillary retinal nerve fiber layer measurements and automated visual fields. Am J Ophthalmol 2004; 138: 218-225.

17 Guedes V, Schuman JS, Hertzmark E, Wollstein G, Correnti A, Mancini R et al. Optical coherence tomography measurement of macular and nerve fiber layer thickness in normal and glaucomatous human eyes. Ophthalmology 2003; 110: 177-189.

18 Medeiros FA, Zangwill LM, Bowd C, Vessani RM, Susanna R Jr, Weinreb RN. Evaluation of retinal nerve fiber layer, optic nerve head, and macular thickness measurements for glaucoma detection using optical coherence tomography. Am J Ophthalmol 2005; 139: 44-55.

19 Leung CK, Chan WM, Yung WH, Ng AC, Woo J, Tsang MK et al. Comparison of macular and peripapillary measurements for the detection of glaucoma: an optical coherence tomography study. Ophthalmology 2005; 112: 391-400.

20 De Moraes CG, Juthani VJ, Liebmann JM, Teng CC, Tello C, Susanna R Jr et al. Risk factors for visual field progression in treated glaucoma. Arch Ophthalmol 2011; 129: 562-568.

21 De Moraes CG, Liebmann CA, Susanna Jr R, Ritch R, Liebmann JA. Examination of the Performance of Different Pointwise Linear Regression. Clin Exp Ophthalmol 2011; e-pub ahead of print 8 September 2011; doi:10.1111/j.14429071.2011.02680.x.

22 Leung CK, Cheung CY, Weinreb RN, Qiu K, Liu S, Li H et al. Evaluation of retinal nerve fiber layer progression in glaucoma: a study on optical coherence tomography guided progression analysis. Invest Ophthalmol Vis Sci 2010; 51: 217-222.

23 Medeiros FA, Zangwill LM, Alencar LM, Bowd C, Sample PA, Susanna R Jr et al. Detection of glaucoma progression with stratus OCT retinal nerve fiber layer, optic nerve head, and macular thickness measurements. Invest Ophthalmol Vis Sci 2009; 50: 5741-5748.

24 Wollstein G, Schuman JS, Price LL, Aydin A, Stark PC, Hertzmark E et al. Optical coherence tomography longitudinal evaluation of retinal nerve fiber layer thickness in glaucoma. Arch Ophthalmol 2005; 123: 464-470.

25 Grewal DS, Sehi M, Paauw JD, Greenfield DS. Detection of progressive retinal nerve fiber layer thickness loss with optical coherence tomography using 4 criteria for functional progression. J Glaucoma 2012; 21(4): 214-220.

26 Leung CK, Liu S, Weinreb RN, Lai G, Ye C, Cheung CY et al. Evaluation of retinal nerve fiber layer progression in glaucoma a prospective analysis with neuroretinal rim and visual field progression. Ophthalmology 2011; 118: 1551-1557.

27 Kanadani FN, Hood DC, Grippo TM, Wangsupadilok B, Harizman N, Greenstein VC et al. Structural and functional assessment of the macular region in patients with glaucoma. Br J Ophthalmol 2006; 90: 1393-1397.

28 Heijl A, Bengtsson B, Hyman L, Leske MC. Natural history of open-angle glaucoma. Ophthalmology 2009; 116: 2271-2276.

29 Hood DC, Fortune B, Arthur SN, Xing D, Salant JA, Ritch R et al. Blood vessel contributions to retinal nerve fiber layer thickness profiles measured with optical coherence tomography. J Glaucoma 2008; 17: 519-528.

30 Budenz DL, Fredette MJ, Feuer WJ, Anderson DR. Reproducibility of peripapillary retinal nerve fiber thickness measurements with stratus OCT in glaucomatous eyes. Ophthalmology 2008; 115: 661-666; e4. 
31 Sehi M, Guaqueta DC, Feuer WJ, Greenfield DS. A comparison of structural measurements using 2 Stratus optical coherence tomography instruments. J Glaucoma 2007; 16: $287-292$

32 Harwerth RS, Vilupuru AS, Rangaswamy NV, Smith EL 3rd. The relationship between nerve fiber layer and perimetry measurements. Invest Ophthalmol Vis Sci 2007; 48: 763-773.

33 Budenz DL, Chang RT, Huang X, Knighton RW, Tielsch JM. Reproducibility of retinal nerve fiber thickness measurements using the stratus OCT in normal and glaucomatous eyes. Invest Ophthalmol Vis Sci 2005; 46: 2440-2443.

34 Tan O, Chopra V, Lu AT, Schuman JS et al. Detection of macular ganglion cell loss in glaucoma by Fourier-domain optical coherence tomography. Ophthalmology 2009; 116: 2305-2314; e1-2.

35 Boden C, Blumenthal EZ, Pascual J, McEwan G, Weinreb RN, Medeiros F et al. Patterns of glaucomatous visual field progression identified by three progression criteria. Am J Ophthalmol 2004; 138: 1029-1036.

36 Bengtsson B, Leske MC, Hyman L, Heijl A. Fluctuation of intraocular pressure and glaucoma progression in the early manifest glaucoma trial. Ophthalmology 2007; 114: 205-209.

37 Heijl A, Bengtsson B, Chauhan BC, Lieberman MF, Cunliffe I, Hyman L et al. A comparison of visual field progression criteria of 3 major glaucoma trials in early manifest glaucoma trial patients. Ophthalmology 2008; 115: 1557-1565.
38 Viswanathan AC, Crabb DP, McNaught AI, Westcott MC, Kamal D, Garway-Heath DF et al. Interobserver agreement on visual field progression in glaucoma: a comparison of methods. Br J Ophthalmol 2003; 87: 726-730.

39 Leske MC, Heijl A, Hussein M, Bengtsson B, Hyman L, Komaroff E. Factors for glaucoma progression and the effect of treatment: the early manifest glaucoma trial. Arch Ophthalmol 2003; 121: 48-56.

40 Teng CC, De Moraes CG, Prata TS, Liebmann CA, Tello C, Ritch $\mathrm{R}$ et al. The region of largest $\beta$-zone parapapillary atrophy area predicts the location of most rapid visual field progression. Ophthalmology 2011; 118: 2409-2413.

41 Leung CK, Chiu V, Weinreb RN, Liu S, Ye C, Yu M et al. Evaluation of Retinal Nerve Fiber Layer Progression in Glaucoma A Comparison between Spectral-Domain and Time-Domain Optical Coherence Tomography. Ophthalmology 2011; 118: 1558-1562.

42 Kass MA, Heuer DK, Higginbotham EJ, Johnson CA, Keltner JL, Miller JP et al. The Ocular Hypertension Treatment Study: a randomized trial determines that topical ocular hypotensive medication delays or prevents the onset of primary open-angle glaucoma. Arch Ophthalmol 2002; 120: 701-713.

43 Miglior S, Zeyen T, Pfeiffer N, Cunha-Vaz J, Torri V, Adamsons I. European Glaucoma Prevention Study (EGPS) Group. Results of the European Glaucoma Prevention Study. Ophthalmology 2005; 112: 366-375. 